\title{
Yeast Extract Promotes Cell Growth and Induces Production of Polyvinyl Alcohol-Degrading Enzymes
}

\author{
Min Li, ${ }^{1,2}$ Xianyan Liao, ${ }^{1}$ Dongxu Zhang, ${ }^{1}$ Guocheng Du, ${ }^{1}$ and Jian Chen ${ }^{1}$ \\ ${ }^{1}$ The Key Laboratory of Industrial Biotechnology, Ministry of Education, School of Biotechnology, Jiangnan University, \\ 1800 Lihu Road, Wuxi 214122, China \\ ${ }^{2}$ College of Life Science and Technology, Inner Mongolia Normal University, Huhhot 010022, China
}

Correspondence should be addressed to Guocheng Du, gcdu@jiangnan.com

Received 9 May 2011; Revised 29 July 2011; Accepted 2 August 2011

Academic Editor: Vasu D. Appanna

Copyright () 2011 Min Li et al. This is an open access article distributed under the Creative Commons Attribution License, which permits unrestricted use, distribution, and reproduction in any medium, provided the original work is properly cited.

\begin{abstract}
Polyvinyl alcohol-degrading enzymes (PVAases) have a great potential in bio-desizing processes for its low environmental impact and low energy consumption. In this study, the effect of yeast extract on PVAases production was investigated. A strategy of fourpoint yeast extract addition was developed and applied to maximize cell growth and PVAases production. As a result, the maximum dry cell weight achieved was $1.48 \mathrm{~g} / \mathrm{L}$ and the corresponding PVAases activity was $2.99 \mathrm{U} / \mathrm{mL}$, which are $46.5 \%$ and $176.8 \%$ higher than the control, respectively. Applying this strategy in a $7 \mathrm{~L}$ fermentor increased PVAases activity to $3.41 \mathrm{U} / \mathrm{mL}$. Three amino acids (glycine, serine, and tyrosine) in yeast extract play a central role in the production of PVAases. These results suggest that the new strategy of four-point yeast extract addition could benefit PVAases production.
\end{abstract}

\section{Introduction}

Polyvinyl alcohol (PVA), a water-soluble synthetic polymer, has commercial applications in the adhesive, paper-coating, and textile industries [1-3]. The material is also of interest for packaging applications, such as bags for dyeing shops, packaging of household items, packaging of monodoses for powders and solid tablets, as well as for liquid concentrates, monodose packaging of chemicals for agriculture such as pesticides, and herbicides [4]. However, it is one of the major water pollutants in industrial wastewater, especially in textile factory wastewater. PVA is not easily decomposed in the environment. Therefore, biological methods were investigated as a means of degrading PVA [5-8].

Researchers worldwide have focused their attention on new microbial isolates $[9,10]$, purification of PVA-degrading enzymes (PVAases) [11-13], and PVA biodegradation mechanisms [13]. PVA has been found to be the only vinyl polymer that can be utilized by some bacteria as a carbon and energy source $[11,14]$. There have been studies on the mechanisms of PVA biodegradation. Sakai et al. reported that PVA was degraded by successive reactions of secondary alcohol oxidase and $\beta$-diketone hydrolase (oxidized PVA hydrolase) from Pseudomonas sp. [15]; this suggests the possibility of formation of $\beta$-diketone structures during the reaction of secondary alcohol oxidase on PVA. $\beta$-Diketone hydrolase catalyzes the hydrolysis of $\beta$-diketone to form a methyl ketone and a carboxylic acid. A different pathway for PVA degradation in Pseudomonas sp. VM15C is the combination of a PQQ-dependent PVA dehydrogenase (PVADH) and oxidized PVA hydrolase (OPH) (an enzyme that acts on an oxidized PVA) [16]. PVADH and OPH constitute an enzyme system for the cleavage of PVA molecules. PVADH introduces $\beta$-diketone groups into the PVA molecule, and OPH subsequently hydrolyzes these $\beta$-diketone groups in oxidized PVA.

Actually, the physiological characteristic of PVAases production by microorganisms in a submerged culture remains sketchy. Our previous studies found that yeast extract is a rate-limiting factor for PVAases production [17]. Other work also relied on yeast extract as an energy source in culturing PVA-degrading bacteria, and the critical component has yet to be identified $[11,18]$.

Therefore, the intention of this work is to quantify the effect of yeast extract on the PVAases fermentation. This study uses an effective mixed culture screened by Chen et al. which is capable of high PVA-degrading enzyme production 
[5]. The observation that yeast extract stimulates cell growth and PVAases production prompted us to conduct further research on the components in yeast extract that are responsible for PVAase production. To our knowledge, this is the first study that shows yeast extract to play a clear promoting role in the production of PVAases.

\section{Methods}

2.1. PVA Materials. PVA 1799 with a 1700 polymerization degree and $99.0 \%$ saponification degree was bought from Sichuan Vinyl Factory (Mianyang, China).

2.2. Microorganisms and Culture Media. The strains used in this study were isolated from PVA-rich soil sampled at Pacific Textile Co. (Jiangsu Province, China), and the ability of the mixed culture in utilizing PVA was investigated in our previous study [9]. The composition of seed and fermentation media was as follows $(\mathrm{g} / \mathrm{L})$ : PVA1799 5, yeast extract 2, $\mathrm{K}_{2} \mathrm{HPO}_{4} \cdot 3 \mathrm{H}_{2} \mathrm{O} 2, \mathrm{KH}_{2} \mathrm{PO}_{4} 0.25, \mathrm{MgSO}_{4} \cdot 7 \mathrm{H}_{2} \mathrm{O}$ $0.1, \mathrm{CaCl}_{2}$ 0.025, $\mathrm{FeSO}_{4} \cdot 7 \mathrm{H}_{2} \mathrm{O} 0.05, \mathrm{NaCl} 0.02$.

2.3. Shake Flask Culture Conditions. Flask culture experiments were performed in $500 \mathrm{~mL}$ flasks each containing $50 \mathrm{~mL}$ medium after inoculating with $10 \%(\mathrm{v} / \mathrm{v})$ of seed culture. The mixed culture was grown in flasks at $30^{\circ} \mathrm{C}$ and $200 \mathrm{rpm}$ for $36 \mathrm{~h}$.

2.4. Batch Fermentation in 7 L Stirred Fermentor. Fermentations were carried out in a fermentor (KF-7 L, Korea Fermentor Co., Inchon, Korea) with $4 \mathrm{~L}$ fermentation medium and an inoculum size of $10 \%(\mathrm{v} / \mathrm{v})$. The $\mathrm{pH}$ was controlled automatically at 7.2 by adding $2 \mathrm{MNaOH}$ or $2 \mathrm{MHCl}$ solution. Aeration rate was $5 \mathrm{~L} / \mathrm{min}$ and agitation speed was controlled at $300 \mathrm{rpm}$.

2.5. Yeast Extract Addition. The type of "yeast" used for the extracts is Saccharomyces cerevisiae. The reagents were purchased from Sangon Biotech (Shanghai) Co., Ltd.

Continuous yeast extract addition: yeast extract was fed to the fermentor continuously at a rate of $0.02,0.04$, or $0.06 \mathrm{~g} / \mathrm{L} / \mathrm{h}$. Feeding of yeast extract started at $18 \mathrm{~h}$ of fermentation and stopped at $30 \mathrm{~h}$.

Single-yeast extract addition: yeast extracts (1, 2, or $3 \mathrm{~g} / \mathrm{L}$ ) were added to the culture broth in flasks at various cultivation times $(0,6,12,18$, and $24 \mathrm{~h})$.

Repeated yeast extract addition: 2-, 3-, and 4-point additions of yeast extract with a final cumulative concentration of $2 \mathrm{~g} / \mathrm{L}$ were carried out at different times $(18,20,22$, and $24 \mathrm{~h})$ in flasks.

2.6. Amino Acids Addition. To find out which amino acids in yeast extract are the key ingredients for the production of PVAases, a mixture of 17 kinds of amino acids (at concentrations identical to those found in yeast extract) was added into the medium. One of the 17 amino acids was omitted each time. Cells were cultured with $\mathrm{NH}_{4} \mathrm{Cl}$ as the nitrogen source, which leads to no detectable PVAases activity.

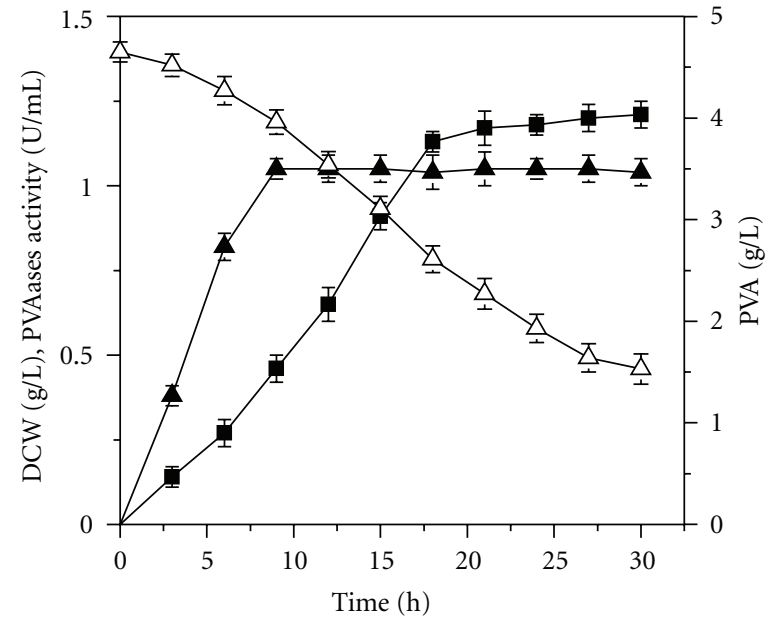

Figure 1: Cell growth and PVAases production in fermentor. PVA $(\triangle)$; DCW $(\boldsymbol{\Lambda})$; PVAases activity $(\mathbf{\square})$.

2.7. Analytical Methods. Cells were harvested by centrifugation at $15,000 \times \mathrm{g}$ and $4^{\circ} \mathrm{C}$ for $20 \mathrm{~min}$. Dry cell weight (DCW) was determined after drying cells at $105^{\circ} \mathrm{C}$ to a constant weight.

Quantitative determination of PVA concentration in culture broth was carried out by spectrophotometric analysis after addition of boric acid and iodine solutions according to the procedure described by Finley [19].

The assay of PVAases activity was based on the methods described by Mori et al. [20]. One unit of enzyme activity is defined as a decrease in absorbance at $1 \times 10^{-3}$ per min at $690 \mathrm{~nm}$ under the specified conditions and is expressed as the total degradation activity for PVA.

To understand the changes of amino acids in the cultivation media during the bacterial growth, the analysis of the amino acids composition in the media was done according to the methods described by Jae-Young et al. [21]. Samples were analyzed with an amino acid analyzer (Agilent1100, USA). All analyses were done in duplicates, and the average value was reported.

\section{Results}

3.1. Batch Fermentation in Fermentor. Yeast extract contains abundant of vitamins, minerals, and amino acids, which are necessary for cell growth and PVAases synthesis [22]. Batch fermentation with yeast extract as nitrogen source in $7 \mathrm{~L}$ fermentor for PVAases production is shown in Figure 1. Cell growth stopped after $9 \mathrm{~h}$ of cultivation, and a maximum DCW of $1.08 \mathrm{~g} / \mathrm{L}$ was obtained. After that, PVAases activity increased continually to $1.23 \mathrm{U} / \mathrm{mL}$ at $30 \mathrm{~h}$. PVA was continuously degraded to $1.53 \mathrm{~g} / \mathrm{L}$ at the end of fermentation. In our previous studies, it was found that the addition of yeast extract was not only advantageous to the growth of the mixed culture, but also propitious to PVAases synthesis [17]. With yeast extract as nitrogen source, we further investigate effects of different addition strategy of yeast extract on cell growth and the production of PVAases by feeding at a constant rate, single bolus addition, and repeated additions. 


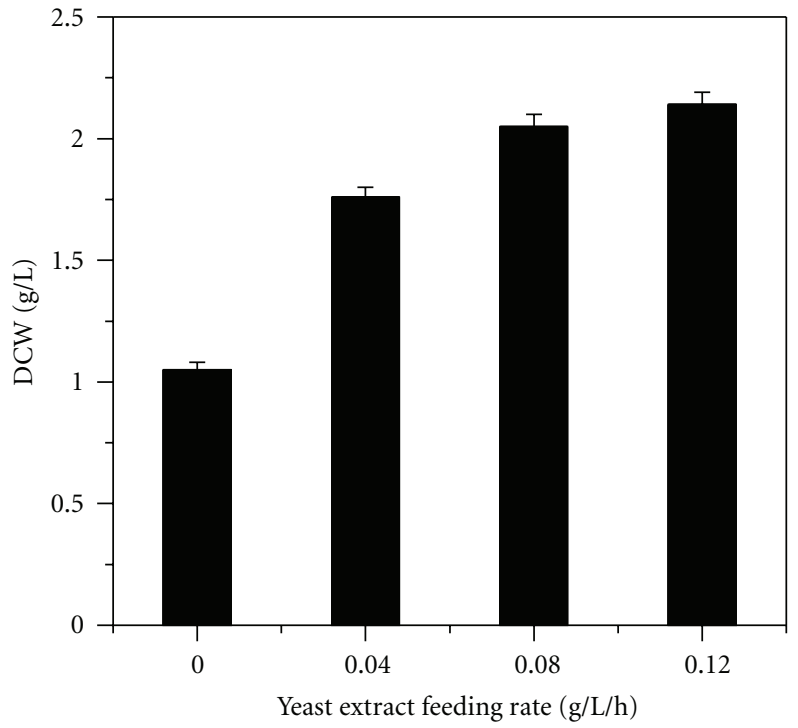

(a)

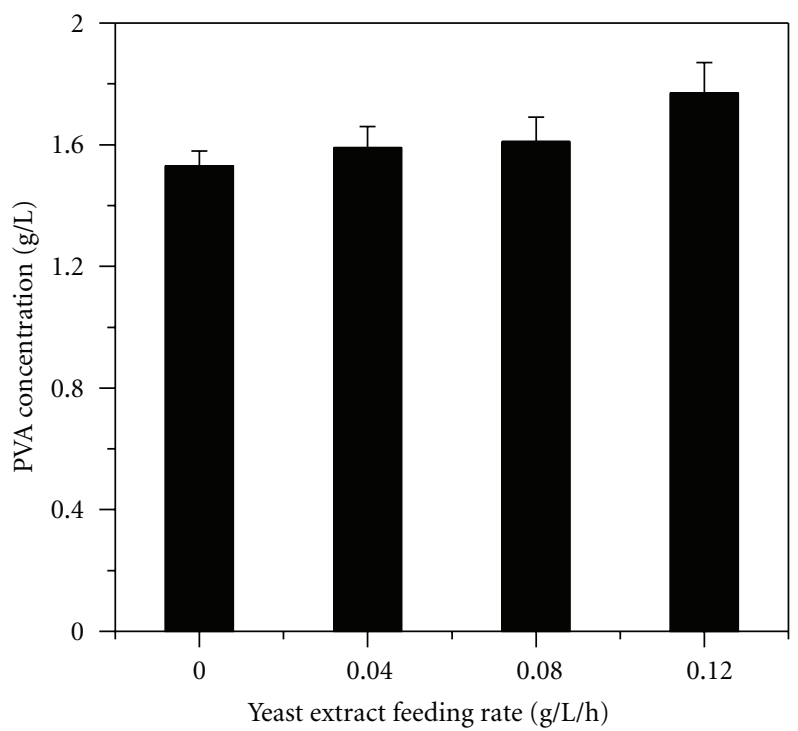

(c)

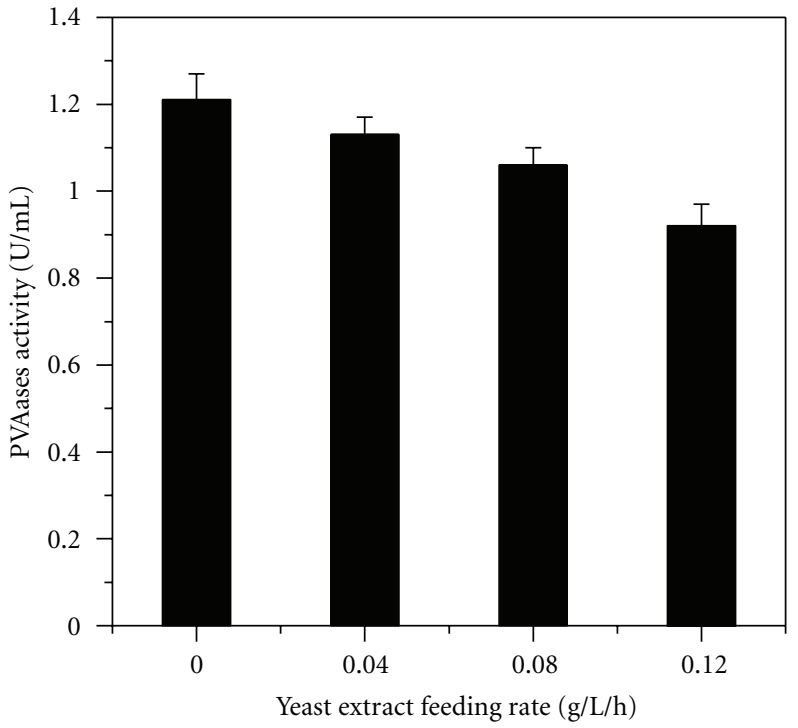

(b)

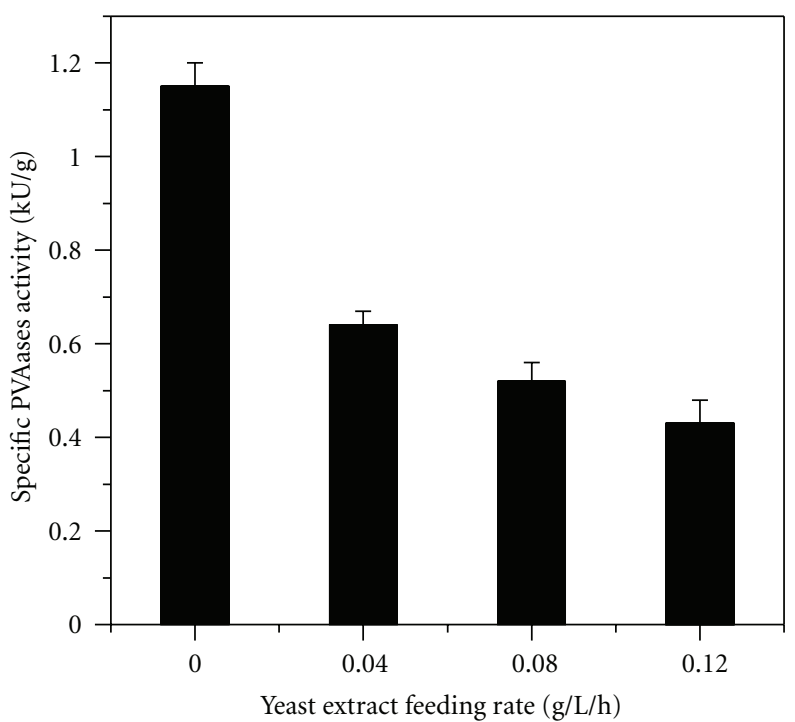

(d)

Figure 2: Effects of continuous yeast extract feeding on cell growth and PVAases production in fermentor.

\subsection{Effect of Continuous Yeast Extract Feeding at Constant} Rates on Cell Growth and PVAases Production in Fermentor. PVAases are increasing rapidly until $18 \mathrm{~h}$, and then keeping a very slow increment. Feeding of yeast extract was therefore started at $18 \mathrm{~h}$ of fermentation and stopped at $30 \mathrm{~h}$.

PVAase activity reflects the total enzyme production capacity of all cells, while specific PVAase activity reflects enzyme production capacity of unit cell. The increase of the enzyme production capacity can be obtained by improving the specific PVAase activity [23]. The kinetic parameter of the specific PVAase activity was obtained from the following equation [24]:

$$
q_{P}=\frac{1}{X} \frac{d P}{d t}=\frac{1}{X} \lim _{\Delta t \rightarrow 0} \frac{\Delta P}{\Delta t} .
$$

Figure 2 shows the effect of yeast extract feeding rate $(0.04,0.08$, and $0.12 \mathrm{~g} / \mathrm{L} / \mathrm{h})$ on cell growth and PVAases production. Cell growth was obviously enhanced with increasing yeast extract feeding rate as compared to the control. However, the highest PVAases activity achieved in each case was lower than the control. Meanwhile, all specific PVAases activities were lower than the control and were negatively affected by feeding rates of yeast extract. As a result, a higher DCW and lower PVAases activity were observed.

Based on the above results, we conclude that it is unsuitable to adopt a continuous yeast extract feeding method to improve PVAases production. It is reasonably believed that addition times and concentrations of yeast extract could affect cell growth and PVAases synthesis. So it is necessary to investigate the timing and strength of yeast extract addition. 


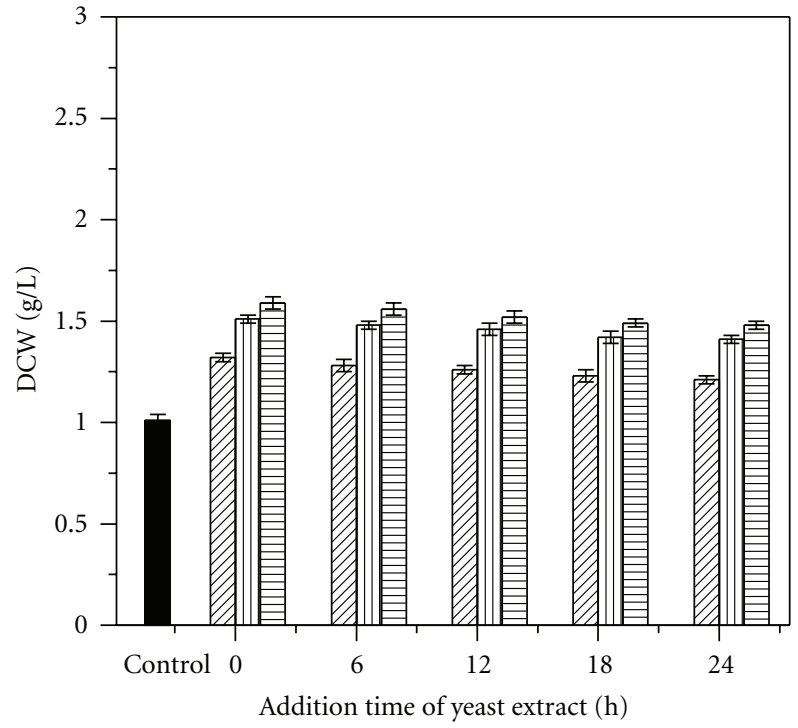

(a)

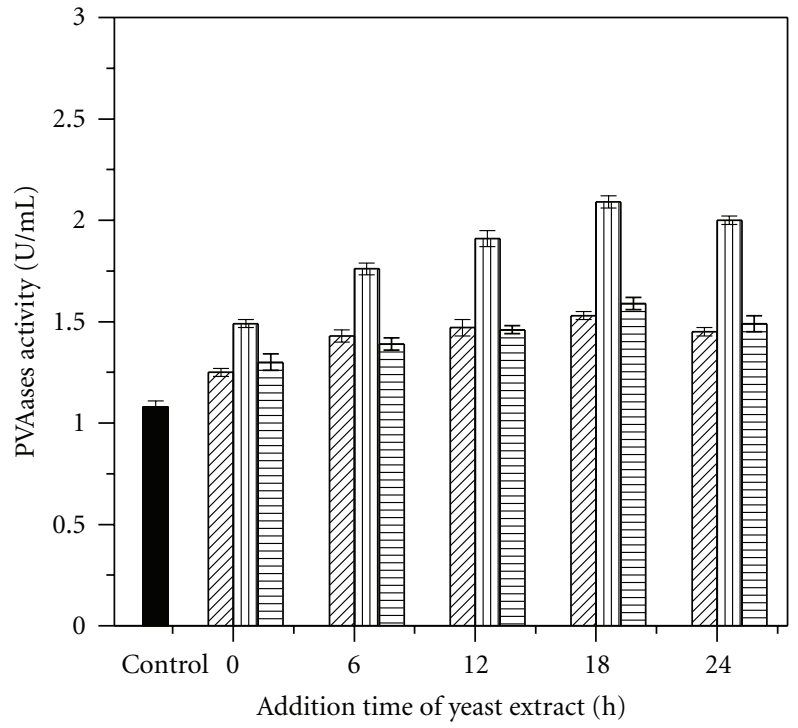

(b)

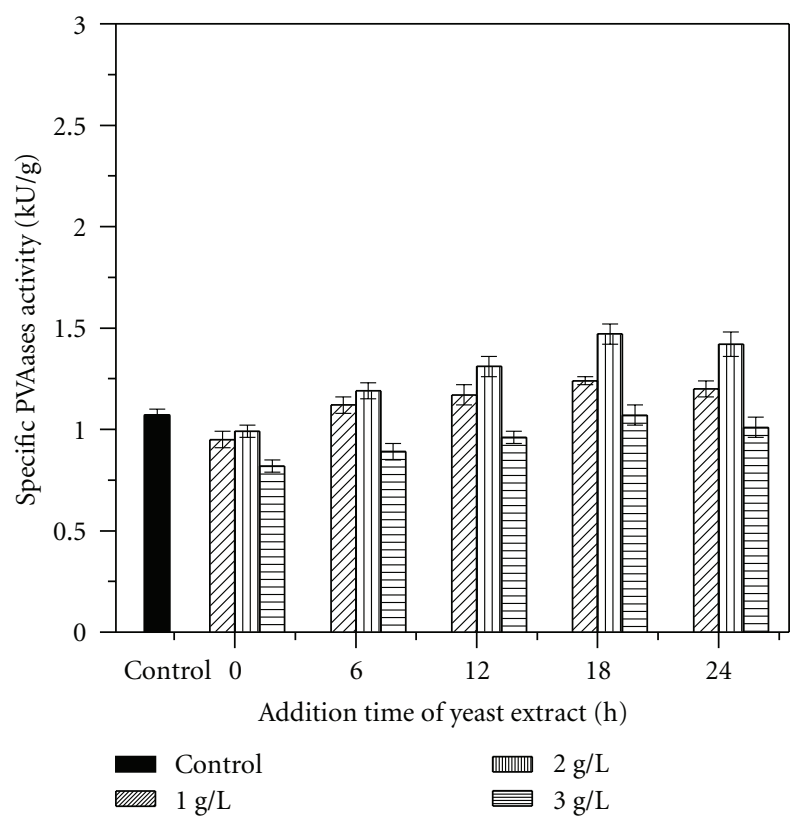

(c)

FIGURE 3: Effect of single yeast extract addition on cell growth and PVAases production with yeast extract concentrations of $1 \mathrm{~g} / \mathrm{L}, 2 \mathrm{~g} / \mathrm{L}$, and $3 \mathrm{~g} / \mathrm{L}$.

The following studies examine the effect of repeated yeast extract addition on cell growth and PVAases production.

\subsection{Effects of Single Bolus Yeast Extract Addition on Cell} Growth and PVAases Production in Shaker Flasks. To obtain higher PVAases activity, yeast extract with concentrations of 1,2 , and $3 \mathrm{~g}$ per liter of fermentation broth was added separately to the culture media, at $0,6,12,18$, and $24 \mathrm{~h}$ of cultivation. DCW and PVAases activity are shown in Figure 3. Single yeast extract addition can effectively promote cell growth and PVAases accumulation simultaneously. And the promotion degree accelerated with delaying of yeast extract addition time.
Irrespective of concentration, yeast extract addition at $18 \mathrm{~h}$ of fermentation resulted in highest PVAases production. Since PVAases activity ceased to increase after $18 \mathrm{~h}$ of fermentation in control, the absence of yeast extract in culture media limited PVAases synthesis. Addition at this time satisfied the necessary of cell growth and PVAases production. For instance, with $2 \mathrm{~g} / \mathrm{L}$ yeast extract addition at $18 \mathrm{~h}$ of cultivation, maximum PVAases activity was $2.09 \mathrm{U} / \mathrm{mL}$, and the corresponding specific PVAases activity was $1.47 \mathrm{kU} / \mathrm{g}$.

Moreover, the highest PVAases activity can be achieved with yeast extract concentration of $2 \mathrm{~g} / \mathrm{L}$ among all three different concentrations. In addition, the maximum PVAases activity achieved with addition of $1 \mathrm{~g} / \mathrm{L}$ yeast extract was 
TABLE 1: Effects of multiple yeast extract addition on cell growth and PVAases production in flask. Number (1) $2 \mathrm{~g}$ yeast extract per liter of culture broth added at $18 \mathrm{~h}$ with a volume of $6 \mathrm{~mL}$; number (2) $1 \mathrm{~g}$ yeast extract per liter of culture broth added at $18 \mathrm{~h}$ and $20 \mathrm{~h}$ with a volume of $3 \mathrm{~mL}$ each time; number (3) $0.67 \mathrm{~g}$ yeast extract per liter of culture broth added at $18 \mathrm{~h}, 20 \mathrm{~h}$, and $22 \mathrm{~h}$ with a volume of $2 \mathrm{~mL}$ each time; number (4) $0.50 \mathrm{~g}$ yeast extract per liter of culture broth added at $18 \mathrm{~h}, 20 \mathrm{~h}, 22 \mathrm{~h}$, and $24 \mathrm{~h}$ with a volume of $1.5 \mathrm{~mL}$ each time.

\begin{tabular}{|c|c|c|c|c|c|c|c|}
\hline \multirow[t]{3}{*}{ No. } & \multicolumn{4}{|c|}{ Addition time } & \multicolumn{3}{|c|}{ Experimental results } \\
\hline & $18 \mathrm{~h}$ & $20 \mathrm{~h}$ & $22 \mathrm{~h}$ & $24 \mathrm{~h}$ & DCW $(\mathrm{g} / \mathrm{L})$ & $\begin{array}{c}\text { PVAases activity } \\
(\mathrm{U} / \mathrm{mL})\end{array}$ & $\begin{array}{l}\text { Specific PVAases } \\
\text { activity }(\mathrm{kU} / \mathrm{g})\end{array}$ \\
\hline & \multicolumn{6}{|c|}{ Concentration of yeast extract $(\mathrm{g} / \mathrm{L})$} & \\
\hline 0 & & & $0(\mathrm{Co}$ & & $1.01 \pm 0.03$ & $1.08 \pm 0.02$ & $1.07 \pm 0.02$ \\
\hline 1 & 2 & & & & $1.42 \pm 0.03$ & $2.09 \pm 0.06$ & $1.47 \pm 0.05$ \\
\hline 2 & 1 & 1 & & & $1.44 \pm 0.03$ & $2.33 \pm 0.07$ & $1.62 \pm 0.07$ \\
\hline 3 & 0.67 & 0.67 & 0.67 & & $1.47 \pm 0.05$ & $2.88 \pm 0.08$ & $1.96 \pm 0.06$ \\
\hline 4 & 0.5 & 0.5 & 0.5 & 0.5 & $1.48 \pm 0.04$ & $2.99 \pm 0.09$ & $2.02 \pm 0.07$ \\
\hline
\end{tabular}

TABle 2: Effects of multiple yeast extract addition on cell growth and PVAases production in fermentor. Number (1) $2 \mathrm{~g}$ yeast extract per liter of culture broth added at $18 \mathrm{~h}$ with a volume of $96 \mathrm{~mL}$; number (2) $1 \mathrm{~g}$ yeast extract per liter of culture broth added at $18 \mathrm{~h}$ and $20 \mathrm{~h}$ with a volume of $48 \mathrm{~mL}$ each time; number (3) $0.67 \mathrm{~g}$ yeast extract per liter of culture broth added at $18 \mathrm{~h}, 20 \mathrm{~h}$, and $22 \mathrm{~h}$ with a volume of $32 \mathrm{~mL}$ each time; number (4) $0.50 \mathrm{~g}$ yeast extract per liter of culture broth added at $18 \mathrm{~h}, 20 \mathrm{~h}, 22 \mathrm{~h}$, and $24 \mathrm{~h}$ with a volume of $24 \mathrm{~mL}$ each time.

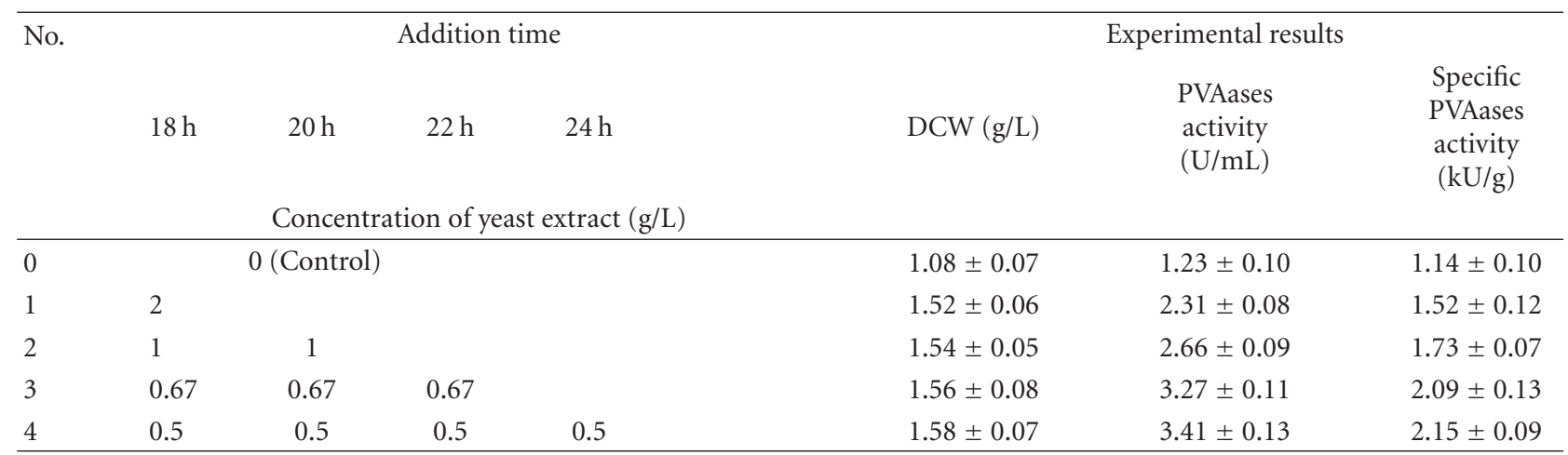

higher than that of $3 \mathrm{~g} / \mathrm{L}$. Because neither too little nor too much yeast extract at one time is optimal, the following studies investigate whether repeated yeast extract additions spaced over time can bring about higher PVAases production than single bolus addition. Our previous results showed that PVAases activity decreased with yeast extract addition after $24 \mathrm{~h}$; yeast extract was therefore added between 18 and $24 \mathrm{~h}$ for PVAases production.

3.4. Effects of Repeated Additions of Yeast Extract on PVAases Production in Shaker Flasks. Yeast extract was added over two time points, three points and four points with a total level of $2 \mathrm{~g} / \mathrm{L}$ between 18 and $24 \mathrm{~h}$, and the results are shown in Table 1. DCW and corresponding PVAases activity increased with the number of yeast extract additions. With four-point yeast extract addition $(0.5 \mathrm{~g} / \mathrm{L}$ of yeast extract each time added at $18 \mathrm{~h}, 20 \mathrm{~h}, 22 \mathrm{~h}$, and $24 \mathrm{~h}$ ), the highest PVAases activity at $2.99 \mathrm{U} / \mathrm{mL}$ and the corresponding specific PVAases activity at $2.02 \mathrm{kU} / \mathrm{g}$ were achieved. These were $43.1 \%$ and $37.4 \%$ higher than single addition. Because PVAases activity of $2.88 \mathrm{U} / \mathrm{mL}$ obtained in three-point yeast extract addition was only slightly lower than that in four-point addition, more frequent additions will unlikely lead to higher PVAases activity. PVAases activity $(2.99 \mathrm{U} / \mathrm{mL})$ obtained by four-point yeast extract addition was $176.8 \%$ higher than the control. Therefore, this new strategy can enhance batch PVAases production.

3.5. Applications of Multiple Points of Yeast Extract Addition Strategies to Fermentor. To prove effectiveness of optimized four-point yeast extract addition in flasks, we further applied this strategy to batch fermentation in a $7 \mathrm{~L}$ fermentor. Table 2 compares PVAases activities between single addition, twopoint addition, three-point addition, and four-point addition of yeast extract. In control, DCW reached a maximum of $1.08 \mathrm{~g} / \mathrm{L}$ after $9 \mathrm{~h}$, and PVAases activity reached $1.23 \mathrm{U} / \mathrm{mL}$ after $30 \mathrm{~h}$. In contrast, with four-point yeast extract addition, PVAases activity reached a maximum of $3.41 \mathrm{U} / \mathrm{mL}$ at the end of fermentation at $30 \mathrm{~h}$.

In four-point yeast extract addition, PVAases activity obtained in flasks $(2.99 \mathrm{U} / \mathrm{mL})$ was lower than that achieved in a fermentor $(3.41 \mathrm{U} / \mathrm{mL})$. Because of a lack of $\mathrm{pH}$ control in shaker flasks, a lower PVAases activity in flasks suggests that besides yeast extract addition, $\mathrm{pH}$ plays a role in PVAase production.

3.6. Role of Amino Acid for the Production of PVAases. Enhanced PVAases activity with the addition of yeast extract 
TABLE 3: Role of amino acids on DCW and PVAases.

\begin{tabular}{|c|c|c|c|}
\hline Nitrogen source & DCW $(\mathrm{g} / \mathrm{L})$ & $\begin{array}{c}\text { PVAases activity } \\
(\mathrm{U} / \mathrm{mL})\end{array}$ & $\begin{array}{c}\text { Specific PVAases } \\
\text { activity }(\mathrm{kU} / \mathrm{g})\end{array}$ \\
\hline Yeast extract & $1.38 \pm 0.03$ & $1.97 \pm 0.05$ & $1.43 \pm 0.04$ \\
\hline AA mixture ${ }^{a}$ & $1.25 \pm 0.02$ & $1.70 \pm 0.04$ & $1.36 \pm 0.03$ \\
\hline AA mixture $\left(\mathrm{Ala}^{-}\right)^{\mathrm{b}}$ & $1.24 \pm 0.04$ & $1.62 \pm 0.06$ & $1.31 \pm 0.03$ \\
\hline AA mixture $\left(\mathrm{Val}^{-}\right)^{\mathrm{b}}$ & $1.23 \pm 0.04$ & $1.64 \pm 0.05$ & $1.33 \pm 0.04$ \\
\hline AA mixture $\left(\mathrm{Leu}^{-}\right)^{\mathrm{b}}$ & $1.24 \pm 0.02$ & $1.69 \pm 0.04$ & $1.36 \pm 0.05$ \\
\hline AA mixture $\left(\mathrm{Ile}^{-}\right)^{\mathrm{b}}$ & $1.26 \pm 0.04$ & $1.66 \pm 0.04$ & $1.32 \pm 0.03$ \\
\hline AA mixture $\left(\mathrm{Phe}^{-}\right)^{\mathrm{b}}$ & $1.25 \pm 0.02$ & $1.64 \pm 0.05$ & $1.31 \pm 0.03$ \\
\hline AA mixture $\left(\mathrm{Met}^{-}\right)^{\mathrm{b}}$ & $1.25 \pm 0.04$ & $1.72 \pm 0.06$ & $1.38 \pm 0.04$ \\
\hline AA mixture $\left(\mathrm{Pro}^{-}\right)^{\mathrm{b}}$ & $1.24 \pm 0.03$ & $1.70 \pm 0.04$ & $1.37 \pm 0.04$ \\
\hline AA mixture $\left(\mathrm{Gly}^{-}\right)^{\mathrm{b}}$ & $1.20 \pm 0.04$ & $0.35 \pm 0.01$ & $0.29 \pm 0.01$ \\
\hline AA mixture $\left(\operatorname{Ser}^{-}\right)^{b}$ & $1.21 \pm 0.02$ & $0.28 \pm 0.01$ & $0.23 \pm 0.01$ \\
\hline AA mixture $\left(\mathrm{Thr}^{-}\right)^{\mathrm{b}}$ & $1.21 \pm 0.03$ & $1.62 \pm 0.04$ & $1.34 \pm 0.04$ \\
\hline AA mixture $\left(\mathrm{Cys}^{-}\right)^{\mathrm{b}}$ & $1.22 \pm 0.04$ & $1.63 \pm 0.05$ & $1.34 \pm 0.04$ \\
\hline AA mixture $\left(\mathrm{Tyr}^{-}\right)^{\mathrm{b}}$ & $1.23 \pm 0.02$ & $0.55 \pm 0.04$ & $0.45 \pm 0.02$ \\
\hline AA mixture $\left(\mathrm{His}^{-}\right)^{\mathrm{b}}$ & $1.25 \pm 0.03$ & $1.68 \pm 0.04$ & $1.34 \pm 0.03$ \\
\hline AA mixture $\left(\mathrm{Lys}^{-}\right)^{\mathrm{b}}$ & $1.24 \pm 0.03$ & $1.64 \pm 0.05$ & $1.32 \pm 0.04$ \\
\hline AA mixture $\left(\mathrm{Arg}^{-}\right)^{\mathrm{b}}$ & $1.26 \pm 0.02$ & $1.67 \pm 0.04$ & $1.33 \pm 0.03$ \\
\hline AA mixture $\left(\mathrm{Asp}^{-}\right)^{\mathrm{b}}$ & $1.23 \pm 0.04$ & $1.67 \pm 0.05$ & $1.36 \pm 0.04$ \\
\hline AA mixture $\left(\mathrm{Glu}^{-}\right)^{\mathrm{b}}$ & $1.21 \pm 0.03$ & $1.61 \pm 0.04$ & $1.33 \pm 0.04$ \\
\hline
\end{tabular}

aA mixture: amino acids mixture contains 17 amino acids, which were detected in yeast extract, respectively, Alanine (Ala), Valine (Val), Leucine (Leu), Isoleucine (Ile), Phenylalanine (Phe), Methionine (Met), Proline (Pro), Glycine (Gly), Serine (Ser), Threonine (Thr), Cysteine (Cys), Tyrosine (Tyr), Histidine (His), Lysine (Lys), Argnine (Arg), Aspartic (Asp), and Glutamic (Glu).

${ }^{\mathrm{b}}$ free of which.

suggests that yeast extract is involved in the synthesis of PVAases. However, the specific component(s) in yeast extract responsible for enhanced PVAases synthesis remains unknown. To identify this, we focused on amino acids, which are the major components of yeast extract. We examined the effect of each of the 17 amino acids that are present in yeast extract (data not shown) on cell growth and PVAases production.

As shown in Table 3, PVAases activity decreased by $78.7 \%, 66.9 \%$, and $83.1 \%$ in the absence of glycine, tyrosine, and serine, respectively; whereas, the absence of other amino acids had relatively little or no effect. It is clear that glycine, tyrosine, and serine are the key amino acids in PVAases synthesis. Table 3 also shows that DCW and PVAases activity with the addition of yeast extract were $10.4 \%$ and $10.5 \%$, respectively, higher than those with the addition of the amino acid mixture. This discrepancy suggests that components in yeast extract other than amino acids may play a role in improving DCW and PVAases activity.

We profiled glycine, tyrosine, and serine during the PVAases production process with and without four-point yeast extract addition. Figure 4(a) shows that these three amino acids were completely exhausted at $18 \mathrm{~h}$ without four-point yeast extract addition. In contrast to the control, these three amino acids keep a stable level from
$18 \mathrm{~h}$ to the end of fermentation with four-point yeast extract addition (Figure 4(b)). This further confirms that depletion of glycine, tyrosine, and serine limited PVAases synthesis.

\section{Discussion}

Yeast extract is usually used as growth stimulants or growth factors for bacteria $[5,23]$. Effects of yeast extract on cell growth and PVAases production by a mixed culture were first investigated in this study.

PVAases are enzymes inducible by PVA [25], and they are synthesized mostly during the stationary phase of cell growth (Figure 1). During cell growth phase, the nutrients are consumed mainly for cell growth but not for enzyme synthesis. Therefore, yeast extract impacted PVAases synthesis heavily when added at the beginning of fermentation, as opposed to the stationary phase (Figure 3 ). However, a shot of yeast extract added at a high concentration $(3 \mathrm{~g} / \mathrm{L})$ does not impact as positively on PVAases production as a shot added at a lower concentration $(2 \mathrm{~g} / \mathrm{L})$ (Figure 3$)$. Excessive yeast extract may inhibit PVAases synthesis. As expected, the strategy of adding yeast extract over multiple number of times maximizes PVAases activity, presumably by avoiding generating inhibitory levels of amino acids. Application of 


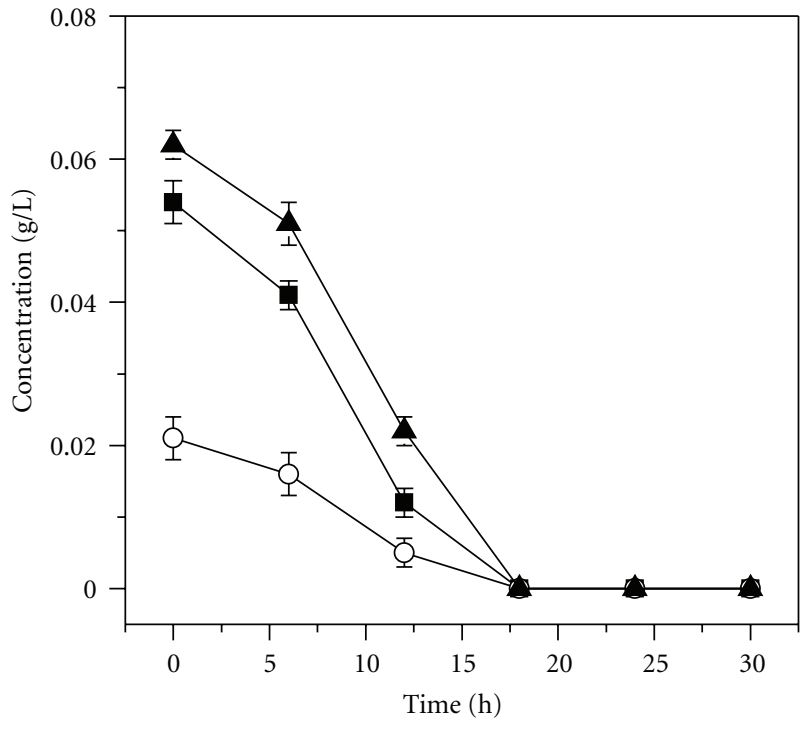

(a)

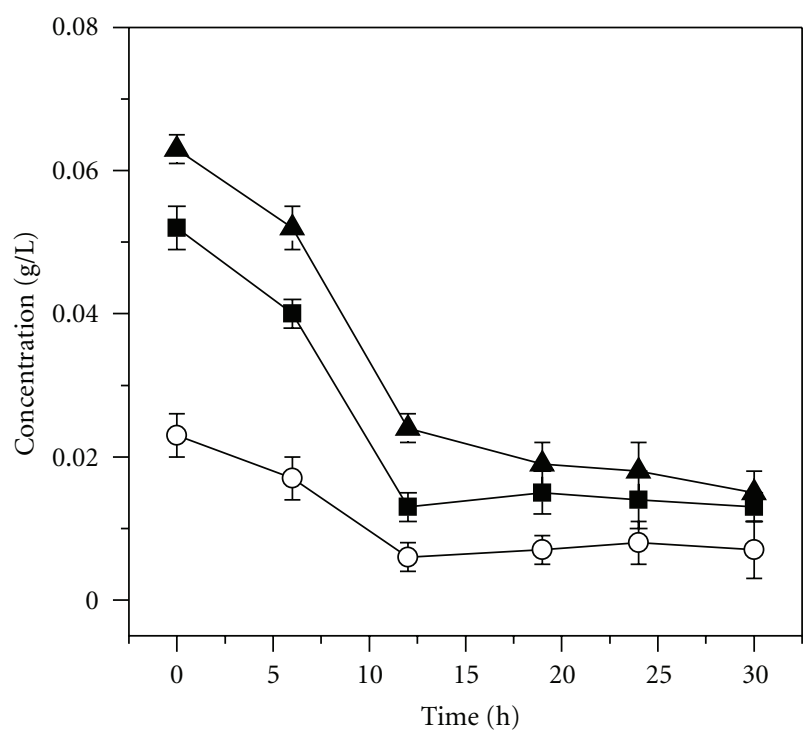

(b)

Figure 4: Profiles of glycine $(\mathbf{\square})$, tyrosine $(\bigcirc)$, and serine $(\mathbf{\Delta})$ during PVAases production with (b) and without (a) four-point yeast extract addition.

this strategy to $7 \mathrm{~L}$ fermentor was also feasible (Figure 4). An increased PVAases activity with the addition of yeast extract indicated that the components in yeast extract enhanced the synthesis of PVAases.

Threonine was proven to be essential for the strain Penicillium sp. to produce PVAases [26]. In our study, it is found that glycine, tyrosine, and serine significantly stimulate the production of PVAases. PVAases are not one but are a collection of PVA-degrading enzymes, such as PVA oxidase, PVA dehydrogenase, and PVA hydrolase. Study on the purification of PVAases will help us to illustrate how these three amino acids accelerate the production of PVAases in the mixed culture.
Thus, several amino acids, including tyrosine, glycine, and serine, had a promoting role in PVAases production. Although tyrosine has been reported by Fujita for its role in PVAases synthesis [22], glycine and serine have not been previously reported for their roles in the production of PVAases. This result suggests that these amino acids may directly participate in the synthesis of PVAases.

\section{Acknowledgments}

This research was financially supported by Program for New Century Excellent Talents in University (NCET-05-0488), a grant from the Major State Basic Research Development Program of China (973 Program, no. 2007CB 714036), and from National Science Fund for Distinguished Young Scholars (no. 20625619) and Program for Changiiang Scholars and Innovative Research Team in University (no. IRT0532).

\section{References}

[1] A. L. R. Melissa, O. S. Cathryn, R. Beth, J. H. Peter, T. Rowan, and P. C. William, "The anaerobic degradability of thermoplastic starch: polyvinyl alcohol blends: potential biodegradable food packaging materials," Bioresource Technology, vol. 100, no. 5, pp. 1705-1710, 2009.

[2] D. Lešinský, J. Fritz, and R. Braun, "Biological degradation of PVA/CH blends in terrestrial and aquatic conditions," Bioresource Technology, vol. 96, no. 2, pp. 197-201, 2005.

[3] C. A. Finch, Polyvinyl Alcohol-Development, John Wiley \& Sons, Chichester, UK, 1992.

[4] E. Ogur, "Polyvinyl alcohol: materials, processing and applications," Rapra Review Reports, vol. 16, no. 12, pp. 1-130, 2005.

[5] J. Chen, Y. Zhang, G. C. Du, Z. Z. Hua, and Y. Zhu, "Biodegradation of polyvinyl alcohol by a mixed microbial culture," Enzyme and Microbial Technology, vol. 40, no. 7, pp. 1686-1691, 2007.

[6] B. C. Kim, C. K. Sohn, S. K. Lim, J. W. Lee, and W. Park, "Degradation of polyvinyl alcohol by Sphingomonas sp. SA3 and its symbiote," Journal of Industrial Microbiology and Biotechnology, vol. 30, no. 1, pp. 70-74, 2003.

[7] Y. Watanabe, N. Hamada, M. Morita, and Y. Tsujisaka, "Purification and properties of a polyvinyl alcohol-degrading enzyme produced by a strain of Pseudomonas," Archives of Biochemistry and Biophysics, vol. 174, no. 2, pp. 575-581, 1976.

[8] E. Chiellini, A. Corti, S. D’Antone, and R. Solaro, "Biodegradation of poly (vinyl alcohol) based materials," Progress in Polymer Science, vol. 28, no. 6, pp. 963-1014, 2003.

[9] Y. Zhang, Y. Li, W. Shen, D. Liu, and J. Chen, "A new strain, Streptomyces venezuelae GY1, producing a poly (vinyl alcohol)-degrading enzyme," World Journal of Microbiology and Biotechnology, vol. 22, no. 6, pp. 625-628, 2006.

[10] J. A. Lee and M. N. Kim, "Isolation of new and potent poly (vinyl alcohol)-degrading strains and their degradation activity," Polymer Degradation and Stability, vol. 81, no. 2, pp. 303-308, 2003.

[11] S. Matsumura, N. Tomizawa, A. Toki, K. Nishikawa, and K. Toshima, "Novel poly (vinyl alcohol)-degrading enzyme and the degradation mechanism," Macromolecules, vol. 32, no. 23, pp. 7753-7761, 1999. 
[12] Y. Kawagoshi and M. Fujita, "Purification and properties of the polyvinyl alcohol-degrading enzyme 2,4-pentanedione hydrolase obtained from Pseudomonas vesicularis var. povalolyticus PH," World Journal of Microbiology and Biotechnology, vol. 14, no. 1, pp. 95-100, 1998.

[13] F. Kawai and X. P. Hu, "Biochemistry of microbial polyvinyl alcohol degradation," Applied Microbiology and Biotechnology, vol. 84, no. 2, pp. 227-237, 2009.

[14] Y. Tokiwa, G. Kawabata, and A. Jarerat, "A modified method for isolating poly (vinyl alcohol)-degrading bacteria and study of their degradation patterns," Biotechnology Letters, vol. 23, no. 23, pp. 1937-1941, 2001.

[15] K. Sakai, N. Hamada, and Y. Watanabe, "Degradation mechanism of poly (vinyl alcohol) by successive reactions of secondary alcohol oxidase and $\beta$-diketone hydrolase from Pseudomonas sp.", Agricultural and Biological Chemistry, vol. 50, no. 4, pp. 989-996, 1986.

[16] M. Shimao, T. Tamogami, S. Kishida, and S. Harayama, "The gene pvaB encodes oxidized polyvinyl alcohol hydrolase of Pseudomonas sp. strain VM15C and forms an operon with the polyvinyl alcohol dehydrogenase gene pvaA," Microbiology, vol. 146, no. 3, pp. 649-657, 2000.

[17] Z. Y. Hu, G. C. Du, Z. Z. Hua, and J. Chen, "Effect of different carbon and nitrogen sources on PVA degradation in a mixed culture and PVA degradation mechanism," Journal of Food Science and Biotechnology, vol. 25, no. 6, pp. 73-78, 2006.

[18] A. Yamatsu, R. Matsumi, H. Atomi, and T. Imanaka, "Isolation and characterization of a novel poly (vinyl alcohol)-degrading bacterium, Sphingopyxis sp. PVA3," Applied Microbiology and Biotechnology, vol. 72, no. 4, pp. 804-811, 2006.

[19] J. H. Finley, "Spectrophotometric determination of polyvinyl alcohol in paper coatings," Analytical Chemistry, vol. 33, no. 13, pp. 1925-1927, 1961.

[20] T. Mori, M. Sakimoto, T. Kagi, and T. Sakai, "Isolation and characterization of a strain of Bacillus megaterium that degrades poly (vinyl alcohol)," Bioscience, Biotechnology and Biochemistry, vol. 60, no. 2, pp. 330-332, 1996.

[21] J. Jae-Young, P. Pyo-Jam, W. K. Jung, and S. K. Kim, “Amino acid changes in fermented oyster (Crassostrea gigas) sauce with different fermentation periods," Food Chemistry, vol. 91, no. 1, pp. 15-18, 2005.

[22] M. Fujita and S. Hashimoto, "Isolation of a bacterium requiring three amino acid for polyvinyl alcohol degradation," Journal of Fermentation Technology, vol. 63, no. 5, pp. 471-474, 1985.

[23] Y. Li, Principles and Technology of Fermentation Engineering, Higher Education Press, Beijing, China, 2007.

[24] J. Wu, Z. Y. Ding, and K. C. Zhang, "Improvement of exopolysaccharide production by macro-fungus Auricularia auricula in submerged culture," Enzyme and Microbial Technology, vol. 39, no. 4, pp. 743-749, 2006.

[25] B. Tang, X. Y. Liao, D. X. Zhang et al., "Enhanced production of poly(vinyl alcohol)-degrading enzymes by mixed microbial culture using 1,4-butanediol and designed fermentation strategies," Polymer Degradation and Stability, vol. 95, no. 4, pp. 557-563, 2010.

[26] Y. Zhang, Y. Li, and J. Chen, "Effects of nutrition condition on producing polyvinyl alcohol (PVA) degrading enzyme by Penicillium sp." Acta Microbiologica Sinica, vol. 44, no. 5, pp. 650-653, 2004. 

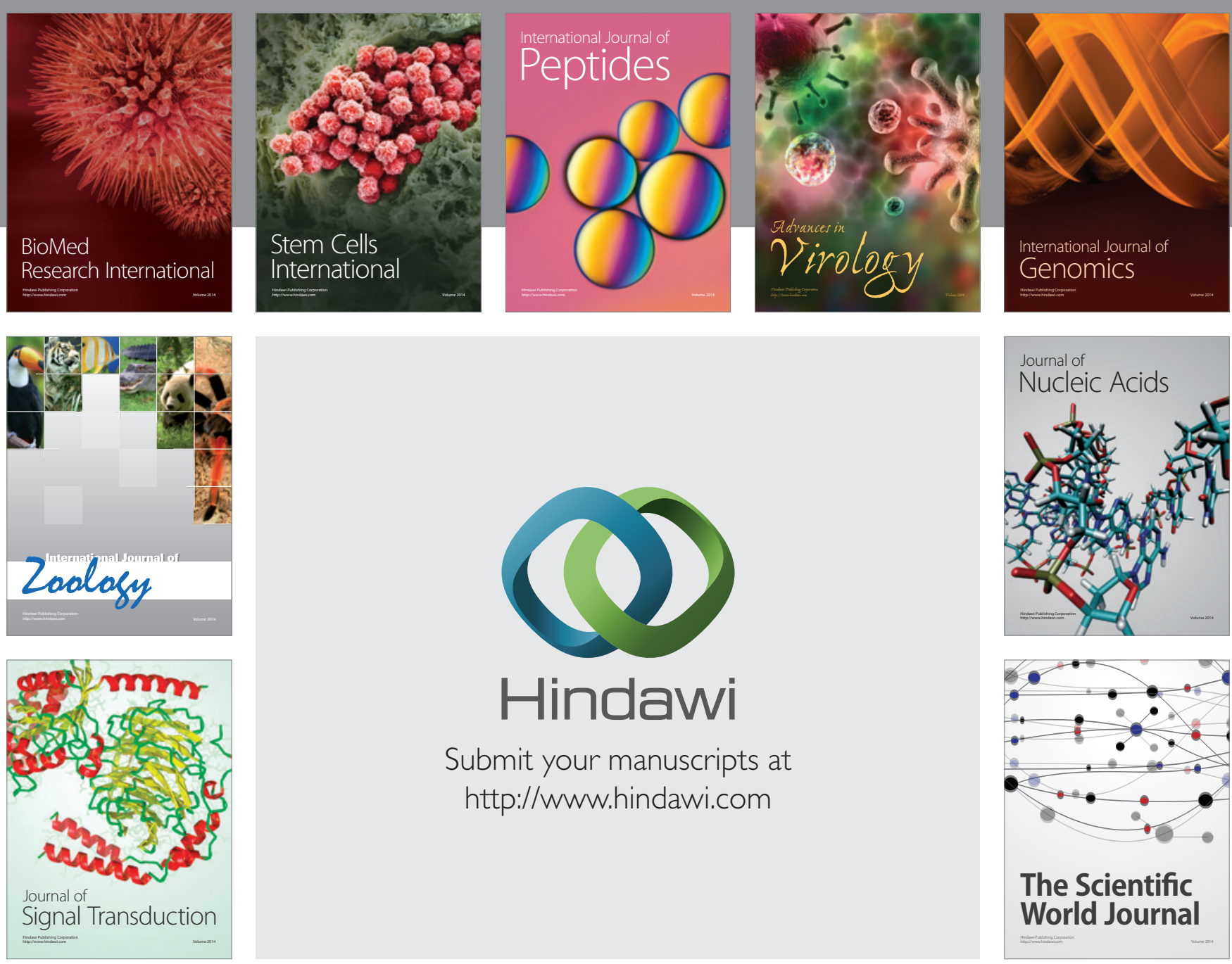

Submit your manuscripts at

http://www.hindawi.com
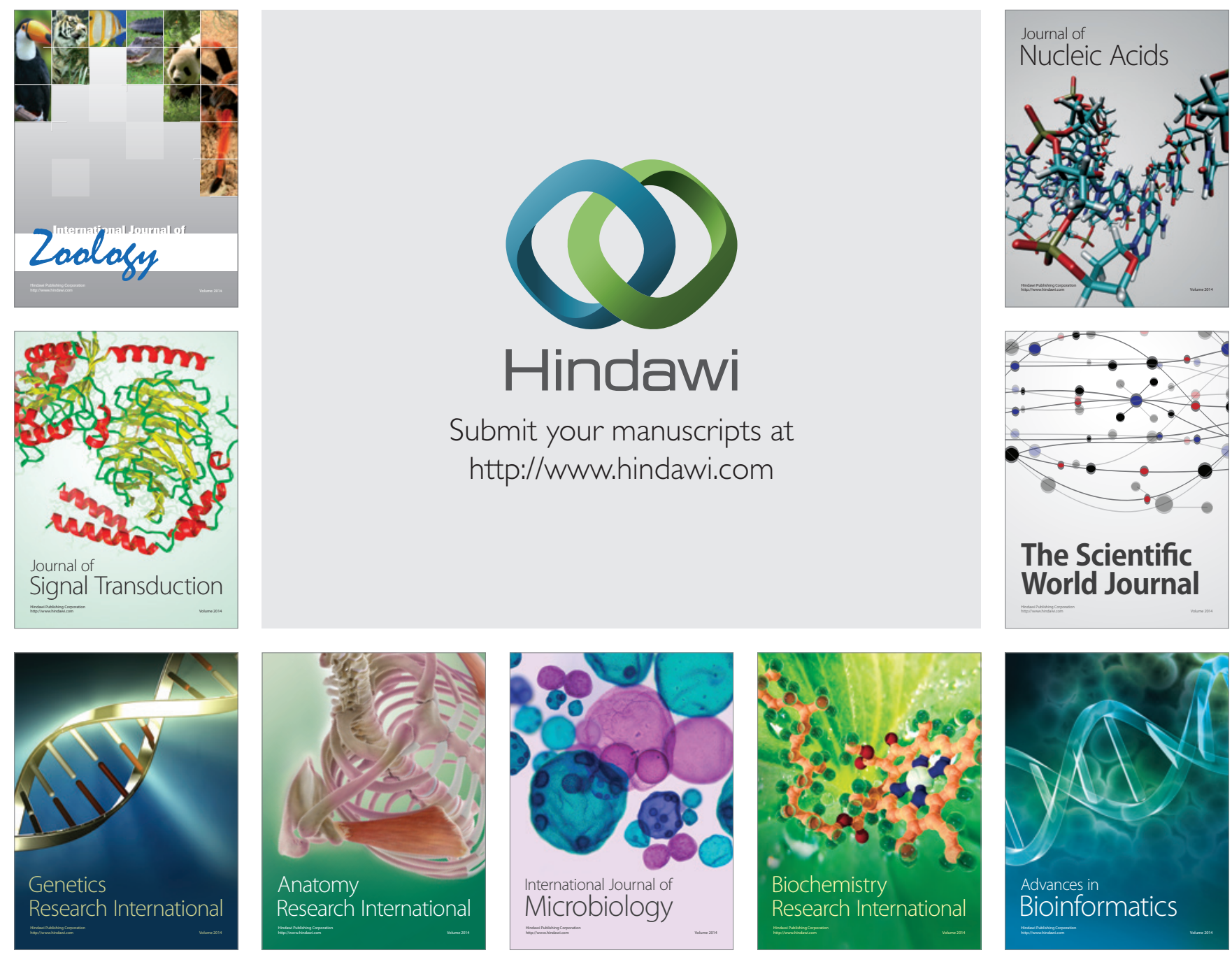

The Scientific World Journal
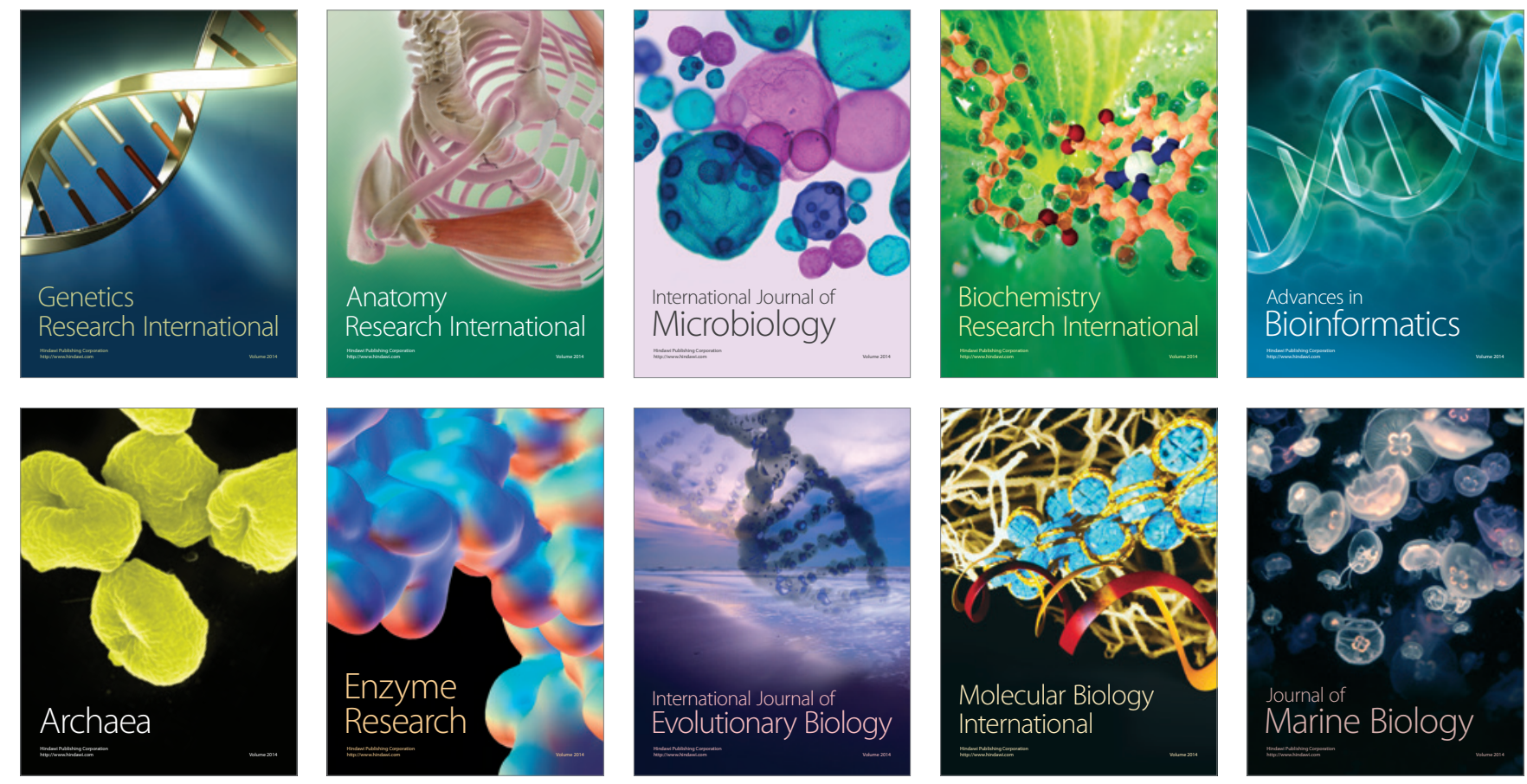